DIGITALCOMMONS

— @WAYNESTATE -
Michigan Journal of Counseling:

Research, Theory and Practice

Volume 40 | Issue 2

Article 4

$12-1-2013$

\title{
Essential Points of a Support Network Approach for School Counselors Working with Children Diagnosed with Asperger's
}

Yuh-Jen Guo

University of Texas at El Paso

Shu-Ching Wang

University of Texas at El Paso

Marilyn F. Corbin-Burdick

University of Texas at El Paso

Shelly R. Statz

University of Wisconsin

Follow this and additional works at: https://digitalcommons.wayne.edu/mijoc

\section{Recommended Citation}

Guo, Y., Wang, S., Corbin-Burdick, M. F., \& Statz, S. R. (2013). Essential Points of a Support Network Approach for School Counselors Working with Children Diagnosed with Asperger's, Michigan Journal of Counseling, 40(2), 28-39. doi:10.22237/mijoc/ 1385856180

This Article is brought to you for free and open access by the Open Access Journals at DigitalCommons@WayneState. It has been accepted for inclusion in Michigan Journal of Counseling: Research, Theory and Practice by an authorized editor of DigitalCommons@WayneState. 


\title{
Essential Points of a Support Network Approach for School Counselors
} Working with Children Diagnosed with Asperger's

\section{Yuh-Jen Guo, Shu-Ching Wang, and Marilyn F. Corbin-Burdick University of Texas at El Paso}

\section{Shelly R. Statz \\ University of Wisconsin}

\begin{abstract}
Asperger Syndrome (AS) presents unique challenges to both families and schools. Children diagnosed with Asperger's possess unparalleled characteristics in cognitive functioning and behavioral pattern. These children need extra attention and assistance in schools. School counselors require a strategy to successfully engage and support these children and to deal with multiple phases of difficulties. A support network approach is proposed in this article to assist school counselors coordinating resources in schools, families, and the community. This approach is discussed with essential points that will help school counselors reach out to families and the community and create a friendly and supportive environment for children diagnosed with Asperger's.
\end{abstract}

\section{Essential Points of a Support Network Approach for School Counselors Working with Children Diagnosed with Asperger's}

Children diagnosed with Asperger's face various types of difficulties. They have displayed dysfunctions in domains such as social interaction, atypical speech and movement patterns, and cognitive and sensory difficulties (Attwood, 2007; Baron-Cohen \& Wheelwright, 2004; Boucher, 2009; Gibbons \& Goins, 2008; Safran, 2005). Their families have to endure excessive stress because of working with these children (Ben-Sasson, Soto, Martínez-Pedraza, and Carter, 2013; Mori, Ujiie, Smith, \& Howlin, 2009). The excessive stress will cause depressive symptoms among parents of these children (Zablotsky, Bradshaw, \& Stuart, 2013). When these children enter the community, they are likely to receive unfavorable reactions from peers and adults.

Yuh-Jen Guo, Ph.D., is an Assistant Professor of Counselor Education with the Educational Psychology and Special Services at the University of Texas at El Paso; Shu-Ching Wang, Ph.D., is a certified School Counselor and Teacher with the Ysleta Independent School District in EI Paso, Texas; Marilyn F. Corbin-Burdick is with the Educational Psychology and Special Services at the University of Texas at EI Paso; Shelly R. Statz is a Licensed Clinical Social Worker with the University of Wisconsin Family Medicine Residency program in Wausau, Wisconsin. 
Children diagnosed with Asperger's are prone to be bullied and show atypical behaviors in social environments (Gill \& Liamputtong, 2013; Sofronoff, Dark, \& Stone, 2011). All these different phases of difficulties mark the complexity noticeable for school counselors working with children diagnosed with Asperger's.

Living under the harsh reality, children diagnosed with Asperger's demand full attention in schools to help them succeed in education. School counselors, whose main mission is to ensure students' academic success, need an all-around strategy to address the educational concerns, which result from the unique difficulties of Asperger's Syndrome (AS). Many books and articles have provided abundant information on the etiology and symptoms, as well as interventions, of AS (Attwood, 2007; Cao, Shan, Xu, \& Xu, 2013; Freed \& Bursztyn, 2012; Hadwin, Baron-Cohen, \& Howlin, 1999; Harpur, Lawlor, \& Fitzgerald, 2006; Hendren \& Martin, 2005; Hull, 2011; Pavlides, 2008; Rubio, 2008; Tsai, 2007); however, school counselors should call for the specifically designed strategy that will help them work effectively with unique difficulties faced by children diagnosed with Asperger's.

Gibbons and Goins (2008) listed major concerns in behavioral, academic, socializing, and transitional issues that are of concerns for schools counselors working with children diagnosed with Asperger's. They had suggested that school counselors should combine resources in schools, families, and the community to serve these children. The authors of this article intended to draw knowledge from literature and to use their experiences in mental health and school counseling to provide essential points that could be used to establish a support network for helping children diagnosed with Asperger's in school education.

\section{Review of Literature}

Asperger Syndrome (World Health Organization [WHO], 2010) is also known as Asperger's syndrome (Wing, 1981, 1998), high-functioning autism (Boucher, 2009), and Asperger's disorder (American Psychiatric Association [APA], 2000). Both the Diagnostic and Statistical Manual of Mental Disorders, 4th edition, Text Revision (DSM-IV-TR) and the International Statistical Classification of Diseases and Related Health Problems, 10th Revision (ICD-10) have listed AS in the category of the pervasive developmental disorders (PDD) (APA, 2000; WHO, 2010). A trend now is to use the term autism spectrum disorders (ASD) to describe autistic disorder, AS, and Pervasive Developmental Disorder-Not Otherwise Specified (PDD-NOS) (Shattuck et al., 2007). The new DSM-V has adopted this trend to give the diagnosis of "autism spectrum disorder" to AS (APA, 2013, p. 51). This means AS will not be a standalone diagnosis but become a diagnosis of ASD with a specified severity level.

Categorizing AS to be a subtype of autistic disorder continues to raise debates among scholars because AS demonstrates noticeable functional differences (Boucher, 2009; Ozonoff, Rogers, \& Pennington, 1991; Safran, 2005; Wing, 1998). AS was described in DSM-IV-TR to show milder abnormality in language and cognitive development, self-help ability, and adaptive functioning (APA, 2000). Developmental abnormalities in social interaction, language and play are less significant (Frith, 2004; Volkmar, Klin, \& Pauls, 1998). Many AS features and symptoms also resemble those of non-verbal learning disability (NLD), pragmatic language impairment (PLI), social phobia, obsessive- 
compulsive disorder, and schizoid personality disorder (Boucher, 2009; Szatmari, 1998). The complexity of AS symptoms definitely reinforces the argument against merging AS with autism in ASD.

\section{Etiology of Asperger Syndrome}

Hanes Asperger once described AS to be "autistic personality disorder" based on common personality traits among AS patients (Attwood, 2007, p. 13). AS is believed to have multiple causes (Boucher, 2009). Genetic and neurological causes are major contributing factors but with unclear mechanisms (Volkmar et al., 1998; Wing, 1998). Hanes Asperger observed a genetic cause which might explain the phenomenon of AS symptoms existing in both parents and children (Asperger, 1991; Attwood, 2007; Volkmar et al., 1998). Brain imaging has been studied to investigate the neurological dysfunctions in AS (Boucher, 2009; Frith, 2004; Ozonoff, Dawson, \& McPartland, 2002; Wicker, 2008). The genetic and neurological factors are crucial in the study of AS (Attwood, 2007).

The Theory of Mind (ToM) has been applied in AS research to explain AS symptoms (Attwood, 2005). ToM describes one's ability to project and exchange mental capacity with others. ToM deficiencies could originate in abnormal brain functioning (Attwood, 2005) and thus explain social impairment of children diagnosed with Asperger's as well as untimely cognitive processing and dysfunctions of empathetic reciprocity (Baron-Cohen \& Wheelwright, 2004). Nonetheless, children diagnosed with Asperger's are known to have "average to above-average intelligence, social and communication deficits, obsessive and narrowly defined interests, concrete and literal thinking, inflexibility, problemsolving and organizational problems, difficulty in discerning relevant from irrelevant stimuli" (Myles, Cook, Miller, Rinner, \& Robbins, 2000, p. 19-20).

Prevalence. AS is showing a prevalence rate of 26 to 36 in every 10,000 school-age children (Ehlers \& Gillberg, 1993). Fombonne (2005) proposed an estimate of 13 in 10,000 for autism, 21 for PDD-NOS, and 2.6 for AS. A smaller prevalence rate and milder symptoms certainly dim the visibility of AS (Fombonne, 2005; Frith, 2004; Volkmar et al., 1998). However, the wide variation and complexity of AS symptoms make it difficult to categorize individuals diagnosed with Asperger's in a homogeneous group (Safran, 2005).

Medical treatment. Contemporary AS treatments focus heavily on reducing emotional and behavioral difficulties. Thus, psychopharmacological medicines are used as the first line of defense to target neuro-psychiatric symptoms (Tsai, 2007). Selective Serotonin Reuptake Inhibitors (SSRIs) "might improve anxiety, compulsive symptoms, repetitive movements, and social features" (Hendren \& Martin, 2005, p. 65). Stimulants and mood stabilizers are prescribed for children's psychiatric and behavioral symptoms (Tsai, 2007). However, Tsai (2007) indicated that the combination of psychotherapy and medicines would significantly enhance the treatment process.

Therapeutic treatment. Various forms of therapeutic interventions have been developed to assist children diagnosed with Asperger's in symptom reduction and skills development. Cognitive skills are incorporated in occupational therapy to improve motor performance on daily tasks (Rodger \& Branden- 
burg, 2009). Intensive therapeutic models have been developed to emphasize on the effects of long treatment hours and structured treatment strategies (Solomon, Necheles, Ferch, \& Bruckman, 2007). The applied behavioral analysis (ABA) and the developmental, individualized, and relationship-oriented (DIR) model are among the key modalities in the intensive therapy approach

(Solomon et al., 2007). These interventions have been implemented in home environment, community agencies, and the schools to manage and improve AS symptoms.

Mental health treatment. The reduction of problematic behaviors and the improvement of daily functioning in homes, schools, and society have become main emphasis of non-medical treatments (Harpur et al., 2006; Myles et al., 2000; Nikopoulos \& Keenan, 2006; Pavlides, 2008; Rubio, 2008; Whalen, 2009). Psychotherapy assists children diagnosed with Asperger's to learn essential coping skills (Bromfield, 2010). It also shows effective treatments on siblings, parents, and peers whom are inevitably impacted by children diagnosed with Asperger's (Harris \& Glasberg, 2003). A wide variety of psychotherapy models is available. Cognitive behavior therapy (CBT) delivers effective results in AS treatment (Tsai, 2007). The ToM concepts inspire the mind reading approach to teach children social skills (Hadwin, Baron-Cohen, \& Howlin, 1999). Art therapy, play therapy and sandplay therapy are available therapeutic models to treat children diagnosed with Asperger's (Cao, Shan, Xu, \& Xu, 2013; Freed \& Bursztyn, 2012; Hull, 2011). Using animal-assisted therapy and martial art in AS treatment adds available resources in the community (Pavlides, 2008; Rubio, 2008).

\section{The Role of School Counselors}

School counselors play an important role in the educational process of children diagnosed with Asperger's. Although school counselors have not directly involved with the diagnosis and medical and therapeutic treatments, they serve the role to collaborate and coordinate services among the family, community, and school (Gibbons \& Goins, 2008). To become a coordinator of various services, school counselors should sketch a strategy gearing toward this function to satisfy the educational needs of children diagnosed with Asperger's. Based on our experiences in serving children diagnosed with Asperger's in the community and schools, we proposed six essential points, which will lay a foundation to a support network approach. This support network approach will be led by school counselors, who play the role of the coordinator to organize the efforts and resources in the schools, families, and the community to better serve these children.

\section{Support Network Approach in School}

Children diagnosed with Asperger's will encounter multiple phases of difficulties in schools (Gibbons \& Goins, 2008). Considering these children's difficulties in socialization and cognitive and behavioral patterns, their learning process will be jeopardized even more when they face more difficulties in the families and community (Foley et al., 2012). Facing the complex situations these children have to battle daily, school counselors should consider utilizing a 
support network approach to fully cover all difficult situations. A support network will reach out to teachers, peers, families, and the community to raise the awareness on AS symptoms. This network can also be connected vertically, from kindergarten to high school, to ensure a smooth transition when these children transit from one school to the other (Gibbons \& Goins, 2008). The purpose of the support network is to go beyond the focus on AS symptoms to bring together the schools, families, and community in a collective effort to assist these children learn and grow. We illustrated these essential points and the support network approach in the following figure to explain how school counselors could construct a support network to link schools, families, and the community togeth-

er.

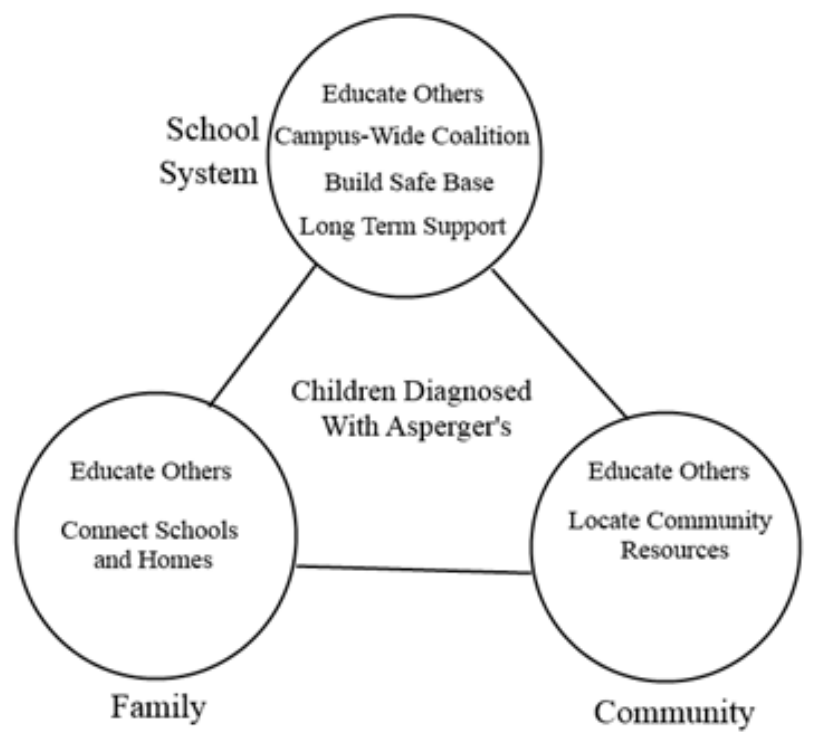

Figure 1. A

\section{Support Network Approach}

The importance of using a support network approach is to turn the focus from AS symptoms to a networking of resources since multiple factors and situations will cause difficulties to be intensified among children diagnosed with Asperger's (Gibbons \& Goins, 2008). These situations, such as the transition of changing schools, should be considered in the strategy to work with these children. Thus, a support network will emphasize on incorporating efforts and resources from teachers, peers, parents, community treatment providers in order to work with these children in schools, families, and the community. Networking certainly brings better benefits by helping these children in different environments and it will cover more grounds than working with these children alone in schools. The six essential points come from the current knowledge and our counseling experiences. These points could be used as the fundamental guidelines to sketch details steps for the construction of a support network. 
Educate others. Misunderstandings about childhood disorders do exist, such as individuals believing children will outgrow their disorders (Young \& Gudjonsson, 2008). Children's strengths may be overlooked and difficulties underestimated due to lack of knowledge about AS (Sainsbury, 2009). Educating others will be a crucial action of advocacy for children diagnosed with Asperger's. This educational effort also serves as an outreach to families and the community by providing accurate information about AS and exchanging important knowledge among schools, families, and the community. School counselors could design guidance curricula and in-service presentations to educate school personnel and fellow students about AS, and they can hold meetings and workshops with parents and work with community service providers to advocate for these children.

Form a campus-wide coalition. A campus-wide coalition will provide a platform for all school personnel, who will be in contact with children diagnosed with Asperger's, to help each other on issues relating to working with these children. Children diagnosed with Asperger's can show difficulties "often related to lack of understanding, stress, or a defensive panic reaction" (Myles et al., 2000, p. 20). This coalition should include school counselors, teachers, special education teachers, and other administrators to work together on promoting the awareness of AS symptoms. The existence of a coalition will enhance its members' ability in working with AS since members will be able to share knowledge and skills. School counselors will serve as the coordinator of this coalition to coordinate the efforts and actions taken to help the children. This coalition will benefit the children and the schools by playing the role as a go-to center and crisis response team, which deliver expertise from different school professionals.

Build a safe base. A safe base is necessary for children diagnosed with Asperger's, who are prone to suffer from co-existing emotional deficiencies or mood problems (Baron-Cohen \& Wheelwright, 2004; Kim, Szatmari, Bryson, Streiner, \& Wilson, 2000). The comorbidity adds uncertainty to the existing difficulties on these children's behavioral and emotional stability. With the possibility of sudden emotional and behavioral outbursts, these children might have to retreat to a safe base where they can re-group and calm down with the help of school counselors. This safe base will be able to reduce unnecessary behavioral or emotional disturbances since these children will be able to receive helps instead of escalating the conflicts in classrooms. School counselors could use the coalition to establish several safe bases where each child will receive attention from a teacher or counselor. This safe base will largely reduce the stress in the classrooms and the anxiety of children diagnosed with Asperger's.

Connect schools and homes. Teachers and parents differ greatly in perceptions of the severity of children's AS symptoms (Barnhill et al., 2000). It shows the discrepancy and distance between schools and homes. School counselors should involve parents in the process of helping their children to win parents' support and to assist parents with their difficulties at homes. A schoolhome connection will serve as a bridge to increase communication between schools and families. Knowing the stress and mental fatigue suffered by the parents of children diagnosed with Asperger's (Ben-Sasson et al., 2013; Mori et 
al., 2009; Zablotsky et al., 2013), school counselors could use this connection to assist parents in reducing their stress and anxiety when going through the 504 application or IEP. This school-home connection will also provide an opportunity for school counselors to help parents seek effective treatments for their children and themselves in the community. Building a connection between schools and homes will benefit children diagnosed with Asperger's while they will receive synchronized support both in schools and at homes.

Locate community resources. Children diagnosed with Asperger's will likely receive treatments in the community (Gibbons \& Goins, 2008). They also have the potential with comorbid disorders, such as depression, bipolar, attention deficit hyperactivity (ADHD), anxiety, and oppositional defiant disorders (Ghaziuddin, Weidmer-Mikhail, \& Ghaziuddin, 1998; Kutscher, 2007). These disorders need community treatment programs to provide necessary medical and mental health interventions. There are also emerging treatment modalities, such as art therapy, play therapy, animal therapy (Freed \& Bursztyn, 2012; Hull, 2011; Pavlides, 2008) and martial arts therapy (Rubio, 2008), which school counselors can refer children for effective treatment. School counselors want to obtain an updated knowledge about available treatment interventions in the community and to maintain an effective communication and collaborative relationship with these treatment programs. Collaborating with community resources will help school counselors cope with comorbid disorders of children diagnosed with Asperger's. This collaboration brings school counselors further understanding of these children's conditions and it also provide community resources where school counselors refer children and parents for effective treatment programs.

Establish long term academic support. Children diagnosed with Asperger's have the potential to achieve their goals when they receive help and support in each step of their education (Graetz \& Spampinato, 2008; Palmer, 2006). These children will be able to attend colleges and become successful in various professions when they have been helped and guided all the way through the educational systems. School transition has been one of the problematic factors that will trigger negative reactions from children diagnosed with Asperger's (Gibbons \& Goins, 2008). How to connect the support networks in different grade schools will become a primary task for school counselors to help these children smoothly transit to new schools. School counselors should expand their on-campus network to connect with other networks in pre-school, elementary, middle, and high schools. When networking becomes vertical, the networks will connect to each other and deliver synchronized assistance through grades. This vertically connected network structure will carry the support for these children all the way until they graduate from high school. The benefit of such connection is that children diagnosed with Asperger's will be familiar with the function of the network and build trust with adults in schools early in education. Thus, they will encounter less intensive difficulties when they have to change schools or go to a new school after graduation. 


\section{Implication}

Considering the complexity of AS (Barnhill et al., 2000; Safran, 2005), school counselors will need a well-designed strategy to assist children diagnosed with Asperger's and to deliver advocacy and counseling services to them. In addition to assisting teachers' classroom behavior management, school counselors should realize that other situations will significantly impact these children's learning in schools (Gibbons \& Goins, 2008). They will need a framework that will cover different needs of these children. The proposed support network approach aims to help school counselors establish a framework to provide all-around support to children diagnosed with Asperger's. A network becomes more effective because it involves people in different positions and setting to work together for these children. It is also beneficial when it will help school counselors reach out to parents and community service providers. This outreach will give school counselors opportunities to assist parents in home environment and to exchange knowledge with community service providers.

The objective of this network approach is to provide school counselors a blueprint to collaborate with on-campus and out-of-campus resources for creating an AS friendly environment. A support network will serve as a platform for professionals in school settings, parents of children diagnosed with Asperger's, and community service providers to find mutual support and expertise exchange for taking care of these children and to promote these children's success in education. The network will also acquire the ability to connect to treatment programs in the community and to build the collaboration between grade schools. The six essential points are proposed to help school counselors construct a support network among schools, families, and the community. This network will be grounded on campus but also garner resources from communities and homes. School counselors will find this concept of a support network beneficial to their work with children diagnosed with Asperger's because they can use this network to deliver services beyond classrooms and to connect with families and the community to provide these children various resources. School counselors can use the six essential points to sketch detailed plans for a support network. These points serve as guidelines that point to directions where school counselors will be able to connect to resources and individuals that are crucial to be included in the support network. A well-established network provides mutual assistance to all partners and supports children diagnosed with Asperger's to succeed in education.

\section{Conclusion}

Encountering children diagnosed with Asperger's in community and school counseling settings brought us challenging tasks. However, our experiences in serving children diagnosed with Asperger's raise the awareness on the lack of a well-connected support system existing among schools, families, and the community. There were times when these children and their parents were caught in the bureaucratic process and misdiagnoses. Although these children will receive the 504 plan or Individualized Education Program (IEP) in schools (Gibbons \& Goins, 2008), not all of them will get it without a fight. Knowing these uphill battles faced by children diagnosed with Asperger's in the educational system, parenting, and community treatments, school counselors will be 
able to anchor a role in this imperfect system and try to improve the situations for these children.

The essential points proposed in this article will be better used as guidelines for planning detail steps in the support network construction. These points lead to domains where detailed action plans will be created and later connected to form a network. We will need to suggest to readers that the essential points and the support network approach have not been empirically tested. It is important to further this discussion by constructing experimental networks to examine the integrity of these points and this approach. Future research will be needed to study the procedures of the network construction and to validate the effectiveness of such a support network in empirical experiments.

\section{References}

American Psychiatric Association. (2000). DSM-IV-TR: Diagnostic and statistical manual of mental disorders (4th ed., Text Re.). Arlington, VA: American Psychiatric Publishing.

American Psychiatric Association. (2013). Diagnostic and statistical manual of mental disorders (5th ed.). Arlington, VA: American Psychiatric Publishing.

Asperger, H. (1991). Autistic psychopathy in childhood. In U. Frith (Ed. \& Trans.), Autism and Asperger Syndrome (pp. 36-92). Cambridge, UK: Cambridge University Press.

Attwood, T. (2005). Theory of Mind and Asperger's Syndrome. In L. J. Baker \& L. A. Welkowitz (Eds.), Asperger's syndrome: Intervening in schools, clinics, and communities (pp. 11-41). Mahwah, NJ: Lawrence Erlbaum Associates.

Attwood, T. (2007). The complete guide to Asperger's syndrome. London: Jessica Kingsley.

Barnhill, G. P., Hagiwara, T., Myles, B. S., Simpson, R. L., Brick, M. L., \& Griswold, D. E. (2000). Parent, teacher, and self-report of problem and adaptive behaviors in children and adolescents with Asperger Syndrome. Assessment for Effective Intervention, 25(2), 147-167. doi: $10.1177 / 073724770002500205$

Baron-Cohen, S., \& Wheelwright, S. (2004). The empathy quotient: An investigation of adults with Asperger Syndrome or high functioning autism, and normal sex differences. Journal of Autism and Developmental Disorders, 34(2), 163-175. doi: 10.1023/B:JADD.0000022607.19833.00

Ben-Sasson, A., Soto, T. W., Martínez-Pedraza, F., \& Carter, A. S. (2013), Early sensory over-responsivity in toddlers with autism spectrum disorders as a predictor of family impairment and parenting stress. Journal of Child Psychology and Psychiatry, 54, 846-853.

Bromfield, R. (2010). Doing therapy with children and adolescents with Asperger Syndrome. Hoboken, NJ: John Wiley \& Sons.

Boucher, J. (2009). The autistic spectrum: Characteristics, causes and practical issues. Thousand Oaks, CA: Sage. 
Cao, H., Shan, W., Xu, Y., \& Xu, R. (2013). Eastern sandplay as a safe container for a combined intervention for a child with Asperger Syndrome: A case study. The Arts in Psychotherapy, 40(1), 134-142.

Ehlers, S., \& Gillberg, C. (1993). The epidemiology of Asperger Syndrome: A total population study. Journal of Child Psychology and Psychiatry, 34, 1327-1350.

Foley, K.-R., Blackmore, A. M., Girdler, S., O'Donnell, M., Glauert, R., Llewellyn, G., \& Leonard, H. (2012). To feel belonged: The voices of children and youth with disabilities on the meaning of wellbeing. Child Indicators Research, 5, 375-391.

Fombonne, E. (2005). The changing epidemiology of autism. Journal of Applied Research in Intellectual Disabilities, 18, 281-294.

Freed, D., \& Bursztyn, A. M. (2012). Art-making with young children with disabilities. In C. Korn-Burstztyn (Ed.), Young children and the arts: Nurturing imagination and creativity (pp. 103-118). Charlotte, NC: Information Age Publishing.

Frith, U. (2004). Emanuel Miller lecture: Confusions and controversies about Asperger Syndrome. Journal of Child Psychology and Psychiatry, 45, 672-686.

Ghaziuddin, M., Weidmer-Mikhail, E., \& Ghaziuddin, N. (1998). Comorbidity of Asperger Syndrome: a preliminary report. Journal of Intellectual Disability Research, 42, 279-283.

Gibbons, M. M., \& Goins, S. (2008). Getting to know the child with Asperger Syndrome. Professional School Counseling, 11(5), 347-352.

Gill, J., \& Liamputtong, P. (2013). Walk a mile in my shoes: Life as a mother of a child with Asperger's Syndrome. Qualitative Social Work, 12(1), 4156.

Graetz, J. E., \& Spampinato, K. (2008). Asperger's Syndrome and the voyage through high school: Not the final frontier. Journal of College Admission, 198, 19-24.

Hadwin, J., Baron-Cohen, S., \& Howlin, P. (1999). Teaching children with autism to Mind-Read: A practical guide for teachers and parents. Hoboken, NJ: John Wiley \& Sons.

Harpur, J., Lawlor, M., \& Fitzgerald, M. (2006). Succeeding with interventions for Asperger Syndrome adolescents: A guide to communication and socialization in interaction therapy. Philadelphia, PA: Jessica Kingsley Publishers.

Harris, S. L., \& Glasberg, B. A. (2003). Topics in Autism: Siblings of children with autism - $A$ guide for families (2nd ed.). Bethesda, MD: Woodbine House.

Hendren, R., \& Martin, A. (2005). Pharmacotherapy. In L. J. Baker \& L. A. Welkowitz (Eds.), Asperger's Syndrome: Intervening in schools, clinics, and communities (pp. 63-81). Mahwah, NJ: Lawrence Erlbaum Associates. 
Hull, K. B. (2011). Play therapy and Asperger's Syndrome: Helping children and adolescents connect, grow, and heal through the art of play. Lanham, MD: Jason Aronson.

Kim, J. A., Szatmari, P., Bryson, S. E., Streiner, D. L., \& Wilson, F. J. (2000). The Prevalence of Anxiety and Mood Problems among Children with Autism and Asperger Syndrome. Autism, 4(2), 117-132. doi:

$10.1177 / 1362361300004002002$

Kutscher, M. (2007). Kids in syndrome mix of ADHD, LD, Asperger's, Tourette's, bipolar, and more! London: Jessica Kingsley.

Mori, K., Ujiie, T., Smith, A., \& Howlin, P. (2009), Parental stress associated with caring for children with Asperger's Syndrome or autism. Pediatrics International, 51, 364-370.

Myles, B. S., Cook, K. T., Miller, N. E., Rinner, L., \& Robbins, L. A. (2000). Asperger Syndrome and sensory issues: Practical solutions for making sense of the world. Shawnee Mission, KS: Autism Asperger Publishing.

Nikopoulos, C., \& Keenan, M. (2006). Video modeling and behaviour analysis: A guide for teaching social skills to children with autism. Philadelphia, PA: Jessica Kingsley Publishers.

Ozonoff, S., Rogers, S. J., \& Pennington, B. F. (1991). Asperger's Syndrome: Evidence of an empirical distinction from high-functioning autism. Journal of Child Psychology and Psychiatry, 32(7), 1107-1122. doi:

10.1111/j.1469-7610.1991.tb00352.x

Ozonoff, S., Dawson, G., \& McPartland, J. (2002). A parent's guide to Asperger Syndrome \& high-functioning autism: How to meet the challenges and help your child thrive. New York, NY: The Guilford Press.

Palmer, A. (2006). Realizing the college dream with autism or Asperger Syndrome: A parent's guide to student success. Philadelphia, PA: Jessica Kingsley Publishers.

Pavlides, M. (2008). Animal-assisted interventions for individuals with autism. Philadelphia, PA: Jessica Kingsley Publishers.

Rodger, S., \& Brandenburg, J. (2009). Cognitive orientation to (daily) occupational performance (CO-OP) with children with Asperger's Syndrome who have motor-based occupational performance goals. Australian Occupational Therapy Journal, 56, 41-50.

Rubio, R. (2008). Mind/Body techniques for Asperger's Syndrome. Philadelphia, PA: Jessica Kingsley Publishers.

Safran, S. P. (2005). Diagnosis. In L. J. Baker \& L. A. Welkowitz (Eds.), Asperger's Syndrome: Intervening in schools, clinics, and communities (pp. 43-61). Mahwah, NJ: Lawrence Erlbaum Associates.

Sainsbury, C. (2009). Martian in the playground: Understanding the schoolchild with Asperger's Syndrome (Revised ed.). Thousand Oaks, CA: Sage. 
Shattuck, P. T., Seltzer, M. M., Greenberg, J. S., Orsmond, G. I., Bolt, D., Kring, S., ... Lord, C. (2007). Change in autism symptoms and maladaptive behaviors in adolescents and adults with an autism spectrum disorder. Journal of Autism and Developmental Disorders, 37, 1735-1747.

Sofronoff, K., Dark, E., \& Stone, V. (2011). Social vulnerability and bullying in children with Asperger Syndrome. Autism, 15(3), 355-372.

Solomon, R., Necheles, J., Ferch, C., \& Bruckman, D. (2007). Pilot study of a parent training program for young children with autism. Autism, 11(3), 205-224.

Szatmari, P. (1998). Differential diagnosis of Asperger Disorder. In E. Schopler, G. B. Mesibov, \& L. J. Kunce (Eds.), Asperger Syndrome or highfunctioning autism? (pp. 61-76). New York, NY: Plenum Press.

Tsai, L. Y. (2007). Asperger Syndrome and medication treatment. Focus on autism and other developmental disabilities, 22(3), 138-148.

Volkmar, F. R., Klin, A., \& Pauls, D. (1998). Nosological and genetic aspects of Asperger Syndrome. Journal of Autism and Developmental Disorders, 28(5), 457-463.

Whalen, C. (Ed.). (2009). Real life, real progress for children with autism spectrum disorders: Strategies for successful generalization in natural environment. Baltimore, MD: Paul H. Brookes.

Wicker, B. (2008). New insights from neuroimaging into the emotional brain in autism. In E. McGregor, M. Núñez, K. Cebula, \& J. C. Gómez (Eds.), Autism: An integrated view from neurocognitive, clinical, and intervention research (pp. 23-41). Malden, MA: Blackwell Publishing.

Wing, L. (1981). Asperger's Syndrome: a clinical account. Psychological Medicine, 11, 115-130.

Wing, L. (1998). The history of Asperger Syndrome. In E. Schopler, G. B. Mesibov, \& L. J. Kunce (Eds.), Asperger syndrome or high-functioning autism? (pp. 11-28). New York, NY: Plenum Press.

World Health Organization. (2010). ICD-10 Version: 2010. Retrieved from: http://apps.who.int/classifications/icd10/browse/2010/en

Young, S., \& Gudjonsson, G. H. (2008). Growing out of ADHD: The Relationship between functioning and symptoms. Journal of Attention Disorders, 12(2), 162-169. doi: 10.1177/1087054707299598

Zablotsky, B., Bradshaw, C. P., Stuart, E. A. (2013). The association between mental health, stress, and coping supports in mothers of children with autism spectrum disorders. Journal of Autism and Developmental Disorders, 43(6), 1380-1393. 